BMJ

Open

Gastroenterology

\title{
Nimble Approach: fast, adapting, calculating and ethically mindful approach to managing colorectal cancer screening programmes during a pandemic
}

\author{
Nancy N Baxter (1) , 1,2,3 Marcia Facey, ${ }^{2,3}$ Arlinda Ruco, ${ }^{2,4}$ Natalie A Baker, ${ }^{2,4}$ \\ Anne Sorvari, ${ }^{2}$ Amina Benmessaoud, ${ }^{2}$ Catherine Dube, ${ }^{5,6}$ Linda Rabeneck, ${ }^{6,7}$ \\ Jill Tinmouth ${ }^{4,6,7,8}$
}

To cite: Baxter NN, Facey M, Ruco A, et al. Nimble Approach: fast, adapting, calculating and ethically mindful approach to managing colorectal cancer screening programmes during a pandemic. BMJ Open Gastro 2022;9:e000826. doi:10.1136/ bmjgast-2021-000826

- Additional supplemental material is published online only. To view, please visit the journal online (http://dx.doi. org/10.1136/bmjgast-2021 000826).

Received 3 November 2021 Accepted 29 December 2021

Check for updates

(C) Author(s) (or their employer(s)) 2022. Re-use permitted under CC BY-NC. No commercial re-use. See rights and permissions. Published by BMJ.

For numbered affiliations see end of article.

Correspondence to Dr Nancy N Baxter;

nancy.baxter@unimelb.edu.au

\section{ABSTRACT}

Objective To describe a conceptual framework that provides understanding of the challenges encountered and the adaptive approaches taken by organised colorectal cancer (CRC) screening programmes during the initial phase of the COVID-19 pandemic.

Design This was a qualitative case study of international CRC screening programmes. Semi-structured interviews were conducted with programme managers/leaders and programme experts, researchers and clinical leaders of large, population-based screening programmes. Data analysis, using elements of grounded theory, as well as cross-cases analysis was conducted by two experienced qualitative researchers.

Results 19 participants were interviewed from seven programmes in North America, Europe and Australasia. A conceptual framework ('Nimble Approach') was the key outcome of the analysis. Four concepts constitute this approach to managing CRC screening programmes during COVID-19: Fast (meeting the need to make decisions and communicate quickly), Adapting (flexibly and creatively managing testing/colonoscopy capacity, access and backlogs), Calculating (modelling and actively monitoring programmes to inform decisionmaking and support programme quality) and Ethically Mindful (considering ethical conundrums emerging from programme responses). Highly integrated programmes, those with highly integrated communication networks, and that managed greater portions of the screening process seemed best positioned to respond to the crisis.

Conclusions The Nimble Approach has potentially broad applications; it can be deployed to effectively respond to programme-specific challenges or manage CRC programmes during future pandemics, other health crises or emergencies.

\section{INTRODUCTION}

The COVID-19 pandemic has had a dramatic impact on healthcare delivery globally. Substantial strain on healthcare systems due to anticipated or actual large numbers of patients with COVID-19 requiring care resulted in non-emergency medical and

\section{Summary box}

What is already known about this subject?

- Colorectal screening programmes have been dramatically affected by the COVID-19 pandemic. Because programmatic screening (where all persons in a target population are invited for screening) requires complex standardised processes and procedures, rapid adaptation is particularly challenging.

What are the new findings?

- The 'Nimble Approach' to managing colorectal cancer screening programmes during COVID-19: Fast (making decisions and communicating quickly), Adapting (being flexible and creative), Calculating (using modelling and monitoring to inform decisionmaking) and Ethically Mindful (considering ethical conundrums emerging from programme responses). Programmes that were highly integrated and organised and that managed more aspects of their screening process than others seemed best positioned to respond to the crisis.

How might it impact on clinical practice in the foreseeable future?

- Adopting the 'Nimble Approach' for pandemic/crisis planning, management and recovery could enable screening programmes to better address emergent and unpredictable challenges.

preventive services being curtailed for periods of time in most jurisdictions. ${ }^{1-5}$ Cancer screening activities were also suspended or considerably slowed down. ${ }^{6-8}$ Programmatic screening (where all persons in a target population are invited for screening) is a recommended approach to reducing the burden of cancer incidence, morbidity and mortality. ${ }^{9}$ These programmes are generally complex and require substantial organisation, with standardised processes and procedures, ${ }^{10}$ thus stopping or starting such programmes 
quickly or making major adaptations is a considerable undertaking.

Organised programmatic colorectal cancer (CRC) screening with faecal immunochemical testing (FIT) is a multistep process that includes invitation, kit administration and return, and follow-up of screen positive patients with confirmation colonoscopy. Although the 'at home nature' of the screening modality avoids contact with the health system initially, screen positive patients do require contact for follow-up investigations. Many jurisdictions have greatly curtailed endoscopy services during periods of the pandemic - for example, on 3 April 2020 the British Society of Gastroenterology recommended temporary suspension of all but emergency and essential procedures $^{11}$ and subsequently the number of colonoscopies performed in England fell by $92 \% .{ }^{12}$ Similar recommendations and reductions in endoscopy were seen in many jurisdictions and required CRC screening programmes to adapt rapidly. ${ }^{13-16}$ There have been a small number of publications detailing steps individual programmes have taken in response to the pandemic, ${ }^{17-22}$ however we lack knowledge and understanding of generalisable approaches taken by screening programmes to adapt to emergent pandemic conditions. This is important for future disaster planning and to help facilitate planning as the current pandemic progresses. We conducted this qualitative study of the responses of population-based CRC screening programmes to the pandemic and developed a conceptual framework for understanding these responses.

\section{METHODS}

We used a qualitative case study method $^{23}$ to examine the experiences of CRC programme leaders to understand, describe and characterise their initial responses to the COVID-19 pandemic (March to December 2020). The study results are reported in compliance with the Standards for Reporting Qualitative Research reporting guidelines. ${ }^{24}$

Purposeful and snowball sampling strategies were used to recruit participants from CRC programmes in North America, Europe and Australasia to participate in semistructured qualitative interviews. Participants included academics/research scientists, decision-makers at the programme and government/senior policy levels, as well as clinicians: gastroenterologists (including department heads), clinical/medical directors, programme/operations directors, and managers of established organised CRC screening programmes that serve large, defined populations (eg, province, a state or a country). Potential participants were contacted by email and were sent study details and consent forms. The consent form was reviewed with participants at the start of the interview and verbal permission to record the interview via Zoom technology was sought and granted.

An experienced qualitative methodologist (MF) conducted 19 semi-structured interviews across seven programmes between June and December 2020. Topic areas included programme characteristics and status, pandemic planning, decision-making and planning about pausing and restarting programmes and challenges to managing (online supplemental appendix 1, Interview Guide). Interviews lasted approximately $45-90 \mathrm{~min}$, were audio-recorded, transcribed verbatim and audited to ensure accuracy and maximise research rigour. ${ }^{25}$ Data collection continued until information redundancy, that is, additional data were similar to what we were seeing in our preliminary analyses. ${ }^{26-28}$

Data analysis, which drew on elements constructivist grounded theory ${ }^{29}$ included an initial process of open, descriptive and in vivo coding aimed at understanding programmes, processes, actions and then focused coding-sorting and organising the codes-to discern similarities and differences between and across them. Memos that described the data and emergent analytical ideas were written, and a codebook was used to track ongoing changes to definitions and to ensure consistency in coding between the two qualitative methodologists (MF and NAB). Data were double coded in instances of discrepancies between coders. NVivo data management software V.12 (QSR International) was used to help organise data and facilitate analysis.

Cross-case analysis of programmes constituted third stage analysis. ${ }^{3031}$ An in vivo code ('being nimble') was discerned as a key common concept across all cases. The next stage of analysis involved identifying the dimensions/categories and meaning of this concept. A final stage of analysis involved discerning the similarities and contradictions within these dimensions/categories.

\section{FINDINGS}

The final sample included seven programmes from North America, Europe and Australasia, and 19 participants including programme managers/leaders (8) and programme experts, researchers and clinicians (11); there were 13 women and 6 men.

In general, there are seven steps to CRC screening process in the programmes: invitation, FIT kit distribution, completion, return, testing, communicating results and diagnosis and treatment (with or without pre-colonoscopy assessment in some cases and colonoscopy). The approach of each programme to these steps is detailed in figure 1. Eligible participants are enrolled in the programmes via identification in multiple health and administrative databases or through their general practitioners (GPs). Participants are invited to screen via letters. Some programmes send test kits with invitation letters, others require requisitions from GPs to central laboratories that then mail kits to patients, or patients pick kits up from the laboratories. Completed kits are mailed back or dropped-off to the laboratories. All interviewed programmes currently use FIT. Patients are informed of their results directly and/or through their GPs. Confirmatory colonoscopy is scheduled by GPs or 

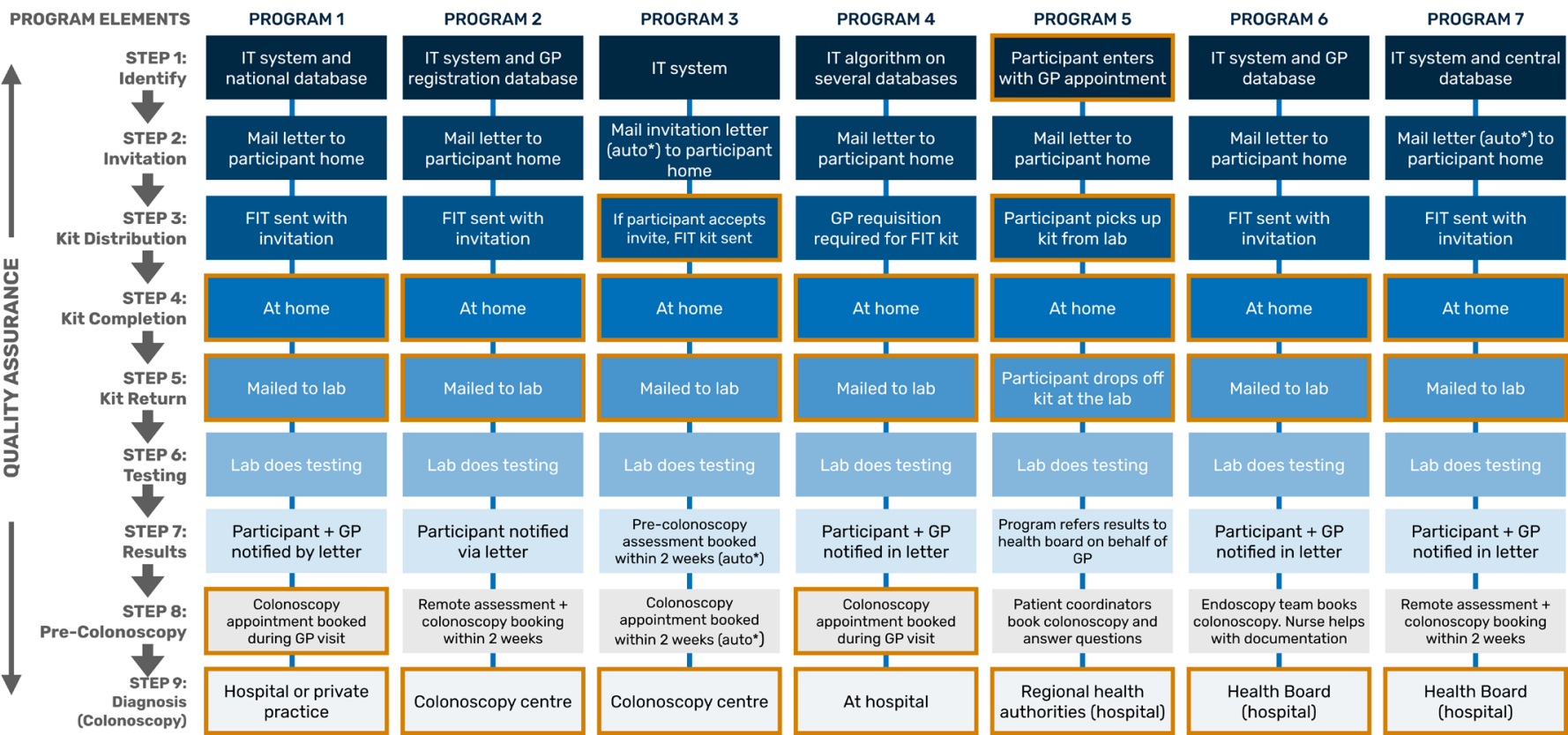

An orange border indicates a screening step that is in control of the participant

* Auto indicates a screening step that is automatically performed by a computer system (algorithm)

Figure 1 Map of the key steps to colonoscopy, during the process for bowel cancer screening in seven international programmes. FIT, faecal immunochemical testing; GP, general practitioner; IT, information technology.

directly by programmes and are done in hospitals and/ or free-standing clinics. All programmes had some form of patient tracking (eg, screening reminder systems). In some programmes, patient/nurse coordinators meet with patients and 'navigate' them through the entire screening process.

\section{The Nimble Approach framework}

The Nimble Approach is a framework that conceptualises how CRC screening programme leaders responded to the COVID-19 pandemic (figure 2). It depicts their ability to 'flex and respond' (Participant (P) 18); to quickly, ethically and creatively adapt and adopt in a context marked by difficult, complex and constantly evolving dynamics and uncertainties ('evolving scene every week or every few days' (P10), in often 'clunky' (P19) bureaucracies and healthcare systems where 'nothing happens fast, new decisions do not happen quickly' (P2) and with no prior roadmaps for decision-making. (online supplemental appendix 2, quote table)

\section{Fast: decision-making and communicating about programmes}

'Fast' characterises the decision-making about whether to suspend or continue programmes and the strategies they used to expedite communication with teams, other programmes and patients. Decisions in the initial phase of the pandemic were made under conditions of uncertainty and constant flux ('really the lack of information that no one had about what was going to happen and what the future held...new information constantly coming through' (P6); 'nothing was etched in' (P5)).
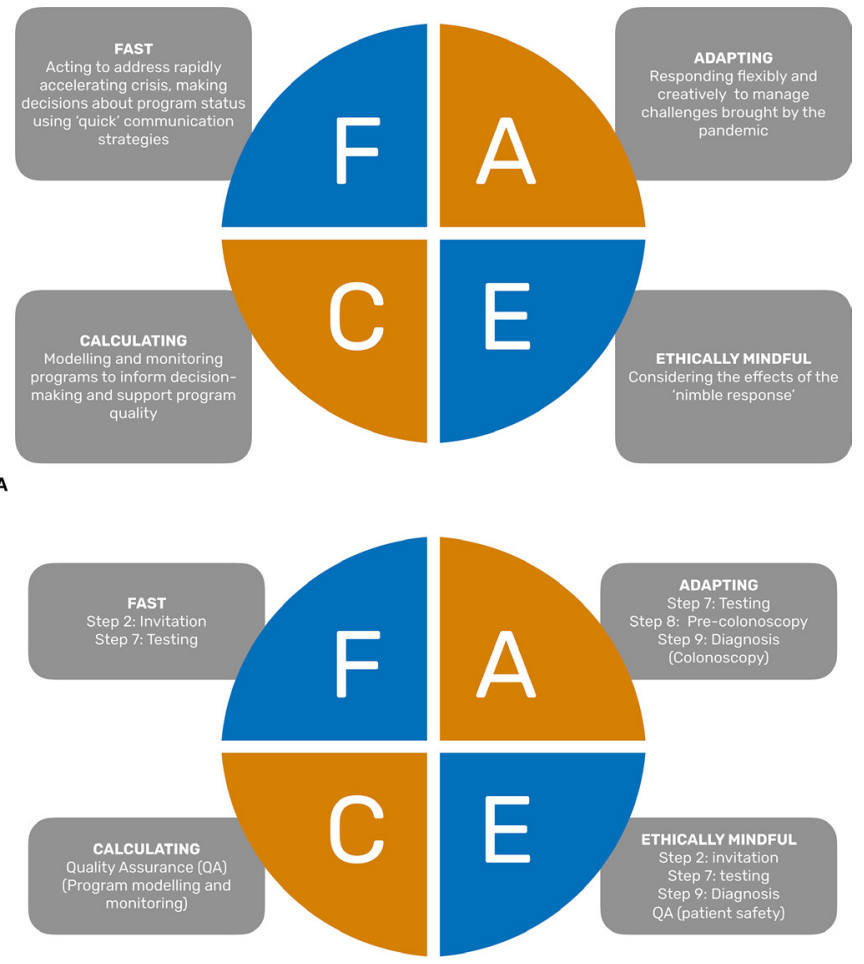

Figure 2 (A) The Nimble Approach: key programme management concepts in response to COVID-19. (B) The Nimble Approach: FACE applied to steps in the bowel cancer screening process. 
Table 1 Representative quotes from interviews related to 'Fast' concept

FAST - acting quickly to address rapidly accelerating crisis-making decisions about suspending or continuing programmes, deploying ad hoc strategies to expedite communication with teams, other programmes.

I think, for instance all through the-those very rapid changes during the height of the pandemic, we were constantly PR6 talking with each other (other screening programs) and saying "are you considering to do, for instance not refer P10 onwards for colonoscopy or are you considering to stop the invitations", or - we have shared, for instance materials that we have produced for informing participants and how the appointment will look like in COVID-19 situations.

... Flexible and nimble and just listening to, you know, see on a daily basis what's going on, what the environment is PR5 like. I don't think any of these things are etched in. And we're all living - learning to live with a little bit of uncertainty. P5

So, very quickly our multidisciplinary team (MDT) meetings moved from face-to-face to virtual. And systems came in PR1 place to allow clinicians to continue to discuss patients and to plan treatment schedules in a virtual way and reduce P15 their own risk of infection. ... There was also a lot of very quickly established collaborations across the oncology sector that really allowed people to work together in a way that we had never seen before. ... there were a number of changes that really were quite significant and happened fast in a way that health reform hasn't occurred in the past.

...There were a number of different organisations and agencies came together who had not done that before. And I think that was quite significant.... a year ago the concept that I could work from home and have Zoom meetings with people ... incredible really. We could never have done this and yet we very quickly established those systems and the same with Telehealth with patients and with MDT's

Only one programme had a pandemic plan, so decisions were ad hoc or on the fly and drawn from programme leaders' expertise and shared experiences ('...we had to learn and develop our processes on the hoof really' (P17); 'we were constantly talking with each other...' (P10)). Participants said their decisions to pause or not pause invites, recalls and testing were made quickly, sometimes with or without government directives, after consideration of risks and outcomes (eg, disease transmission risk, resource capacity).(table 1)

In complex programme organisations, decision-making and approvals for policy and internal and stakeholder communications are multitiered and often slow. During the pandemic, programmes expedited these processes using strategic language. 'Technical guidance' one participant said, was used 'to get around the idea that we were making policy or giving them instructions' (P18). In another programme 'guidances', which generally take weeks/months to be approved and disseminated were reframed as 'tip sheets' so that vital information could be quickly and widely shared ('If you create what we call a 'tip sheet,'...then you can actually disseminate it, send it around as much as you want to whoever you want' (P3).

With the lockdowns, patients were advised to avoid or reduce travel, workers were obliged to work from home and communication became a challenge. Participants said they increased their use of technologies such as telemedicine, webinars and videoconferencing. Where these had not been fully embraced, they were immediately incorporated into daily practice ('very quickly our multidisciplinary team meetings moved from faceto-face to virtual') (P5), including virtual clinics for patients ('...what I've seen in my institution is very promptly they would be assessed by video, by telemedicine by the cancer surgery team. (P3)). Social media was also used to communicate with the public about programme status.

\section{Adapting: testing/colonoscopy Services}

A second feature of the Nimble Approach framework is adapting. It refers to the ways programme leaders adapted and adopted their management of testing/colonoscopy capacity, access and backlogs during COVID-19. Screening programmes access colonoscopies through hospitals and freestanding clinics. With hospitals ramping down non-essential services, closures of some free-standing clinics and reduced hospital capacity and resources (redeployed staff, personal protective equipment shortage, limited capacity for colonoscopies), programme leaders responded to the need for continued access using a prioritisation process. One participant defined prioritisation as "putting on hold something that's not absolutely urgent for a given individual's immediate health' (P2). A key question that guided prioritisation decisions was 'in a circumstances where you've got very little capacity, who do you prioritise?' (P18). Several streams of patients who needed access to colonoscopy services had to be considered: symptomatic, FIT positives and surveillance (post cancer screening follow-ups, postpolypectomy surveillance).(table 2 )

Prioritisation reflected a pyramid shape, with 'the smallest number of high-risk people at the top, out to the largest number of people at average population risk, at the bottom' (P18). Participants said patients were prioritised via a process of risk stratification, based on whether their cases were urgent and emergent, whether they needed care but could be delayed during the pandemic and whether they could wait until after the pandemic. Parameters for stratifying patients varied between programmes but included age, gender, FIT result or concentration ('the higher the FIT concentration, the higher the risk' $(\mathrm{P} 6, \mathrm{P} 7))$, on risk for colon cancer, and on acuteness of symptoms.

Symptomatic patients are outside screening programmes but they influence colonoscopy capacity and 
Table 2 Representative quotes from interviews related to 'Adapting' concept

ADAPTING - responding flexibly and creatively to manage challenges brought by the pandemic. How programme leaders adapted and adopted their management of testing/diagnosis/colonoscopy capacity, access and backlogs during COVID-19.

...we came up with different priority levels; A being the top, very urgent and B and C but we also increased, added this Category D, for 'DO NOT Perform', at any time, in or out of the pandemic, there's this list of screening, average risk PR4 colonoscopy and surveillance for low-risk adenomas that should just never be done, just remove them from your list, you know.

So certainly there was a backlog, and we undertook, we looked at creating a bit of a lift for the health authorities, of their patients, and we created a bit of an algorithm to risk stratify the patients, incorporating how long they've been waiting since their abnormal FIT, and gender, patient age and the FIT value.

So, ther - there were discussions among the leads in the screening centres about how you would identify those ones who are PR3
particular risk. So one suggestion was that you would base it on the FIT concentration, the higher the FIT concentration the
higher the risk and there is truth in that.

FIT, faecal immunochemical testing.

access. Several participants explained that some symptomatic patients were sometimes prioritised over FIT + patients where the latter were considered 'not urgent, urgent' (P2, P9). Patients with positive FITs and a family history of cancer were prioritised over those with no family history. Patients undergoing surveillance also had lower priority than FIT positives and therefore may not have had access to colonoscopies during the pandemic.

Revising screening protocols/adopting new CRCCOVID-19 guidelines was another adaptive undertaking by programmes. These guidances, which included descriptions of prioritisation schemas, helped to create additional colonoscopy capacity and clear backlogs at programme restart by reducing the number of people eligible for colonoscopies. Another participant explained how in their programme, the protocol for screening using FIT and colonoscopy was being changed to facilitate greater colonoscopy capacity by using FIT for people who are at average risk or have had low risk polyps in the past (P2).

\section{Calculating - modelling and monitoring programmes}

There was extensive use of modelling and monitoring to inform decision-making about programme pauses and restarts, capacity management, impacts and harms mitigation. Participants said they used modelling to evaluate options ('if you want to do this, is that worse than doing that') and to answer questions about the consequences of the pause and restart ('if bowel screening misses this many people and extends the interval for this many people, how many cancers (do) we think we get' (P18); 'how many people will have died because the screening process was not in place' $(\mathrm{P} 7)$. For programmes that did not pause, modelling was used to predict potential harms ('modelling suggest there's a significant reduction in lives saved if we were paused' (P8)) and to support decision-making (table 3).

At restart, participants said they used modelling to inform future planning, to answer questions such as 'given that we are going to have reduced capacity for colonoscopies, what should we use them for' (P18) and 'what should be done in the event of a second wave' (P14). Modelling was also used to understand system capacity, to answer questions such as length of time to colonoscopy, length of time to clear colonoscopy backlogs, programme recovery and how to 'risk stratify the patients' who were waiting for colonoscopies.

Increased monitoring (additional analyses and evaluations to routine monitoring) of programme outcomes and performance was another calculating activity that programme leaders used to manage programmes. Monitoring could, participants said, inform decisions as the pandemic progressed, understand attitudinal changes toward screening uptake ('that's one of the most serious considerations for any pause...' (P10) and retention rates ('I think the effect that COVID-19 has on behaviour and

\section{Table 3 Representative quotes from interviews related to 'Calculating' concept}

\section{CALCULATING - modelling and monitoring programmes to inform decision-making and support programme quality.}

... we used the model to see how we could reduce the colonoscopy demand in such a way that it would have the colonoscopy demand. We looked at skipping an age group for invitation, we looked at extending the interval and we looked at lowering the cut-off. And we found that lowering the cut-off was the best way to reduce colonoscopy demand without, well at least with the least impact on preventive deaths.

I think part of the issue is that people are a bit scared to come in for colonoscopy, and I think one of the things that we're PR2 anticipating once the colonoscopy starts again, is we may actually not have as good an uptake of colonoscopy as we P6 were expecting, because I think people are still very wary about coming into hospitals. 
Table 4 Representative quotes from interviews related to 'Ethically Mindful' concept

ETHICALLY MINDFUL - considering the effects of the 'nimble response'. Programme access challenges-delays, bottlenecks created in programme process (invitations, testing, diagnosis, capacity management) and quality assurance concerns (emotional well-being and safety of programme patients).

... and we measure and evaluate the quality of the programme in every step of the process. So the concept is that cancer screening PR4

is a process. First of all, its population based and organised... Number 2, it's not a single test, it's a process. It's a series of steps and as we run and operate the programme we measure and report on the quality and performance of every step in the path.

It became very clear early on in the pandemic that colonoscopy had just stopped. People weren't getting colonoscopies, except under extreme emergency situations. And it became, you know, pretty clear that we were building up a backlog of people who weren't going to get their colonoscopy for the foreseeable future.... I think it's ethically unsound to say to somebody, "You've got a positive test but it's not very positive, so you'll just have to wait" because you're going to engender a lot of anxiety by doing that.

...in some smaller communities there weren't any cases of COVID-19. And so those smaller centres wanted to continue with screening.... I think that was a bit difficult for places where they basically had no COVID-19. They knew there were these patients waiting to have colonoscopies done and they weren't working. They had all these staff, all of these nurses at the endoscopy clinic, these physicians that didn't have anyone to scope. And they felt like, you know, these resources are so precious to us because, you know, they're limited, that they were being wasted now.

people's willingness to participate in screening is going to be very interesting' (P5)).

\section{Ethically mindful- considering dilemmas in COVID-19 response management}

Being ethically mindful, the fourth feature of the Nimble Approach framework characterises the participants' considerations of ethical conundrums that emerged in their adapting and calculating approaches to programme management; that is, issues related to invites/recall letters, testing, prioritisation and capacity management. The concept of screening as a process and not a one-off test informed these ethical considerations. There is, one participant said, 'a moral obligation on the part of the State that if it is going to invite people to screen then it must have capacity to complete the process' (P18). This ethical dilemma was suggested in the question to one programme leader from a clinician, 'how can you offer all of these people screening, when I tried to get them into follow-up and there is no place, I can put them in?' (P14) (table 4).

Participants noted concerns about bottlenecks for FIT testing and colonoscopies; kits were returned but not tested or had to be spoilt (P7, P10); and people were FIT positive but 'were not scheduled for a colonoscopy yet' (P14). One participant maintained that it was 'inappropriate to have literally thousands of people with positive results and no way of investigating' (P12). They also expressed concerns about the uneven effects of COVID-19 and the associated uneven access to colonoscopies. Colonoscopies were restricted or paused depending on COVID-19 case numbers and regions; decisions to provide them were localised, sometimes 'facility by facility' (P3) in the same city. This resulted in idled resources while patients waited for colonoscopies.

Participants also noted concerns about patient safety during colonoscopies ('how can WE guarantee that if somebody steps into a colonoscopy centre, that there is no coronavirus, that the colonoscopy centre can guarantee 1-1/2 metres distance?' (P11), and about patients' emotional well-being related to delayed diagnoses; for example, FIT + patients who were unable to get prompt access to confirmatory colonoscopies. Their concerns also extended to screening retention rates, potential harms of delayed diagnoses and undiagnosed cancers.

\section{The tensions of the Nimble Approach}

There were, as suggested in the 'ethically mindful' discussion, tensions inherent in the Nimble Approach; these were partly shaped by the nature of the screening environment (eg, population size; programme design and governance (state/national), political environment and the regionalised effects of COVID-19). There was tension between 'fast' decision-making, 'adapting' and programme governance where state-level governed programmes have one 'on/off switch' (P2) but decisions needed to be localised because of uneven COVID-19 effects. Regionalised stop/restart decisions led to 'huge inconsistences' in programmes (table 5).

Tensions were also suggested between 'fast' and 'calculating' and programme governance. Delays in getting necessary 'fulsome information' (P6) from governing bodies and health boards slowed modelling or measuring activities that could inform programme quality and decision-making. Further, not all programmes had the resources needed to conduct increased or additional monitoring activities; these activities had to be outsourced to get necessary data in a timely way. Although programmes with capacity for additional modelling might be able to more effectively adapt to changing conditions (eg, use data to develop more effective prioritisation schemas), the constantly evolving nature of the pandemic and corresponding shift in knowledge might inhibit their ability to be nimble. Also, the quick pivot to increased technology use was not universally successful. In some programmes, virtual clinics were not fully used because providers had uneven access to, and inadequate training and/or comfort with, these technologies. In some programmes, information technology systems were described as cumbersome in their patient tracking and recall capabilities.

There was also tension between 'adapting' (colonoscopy/prioritisation) and 'calculating' (quality assurance, patient safety and modelling). There were, one 
Table 5 Representative quotes from interviews related to 'Tensions' concept

The tensions of the Nimble Approach.

I don't think it [programme management] was nimble at all. [Laughter] ...it's very clunky because it's actually run from a huge bureaucracy.... It's not run anywhere local, there's no nimble about it.

It seemed like a long time; it could have been 3 weeks I'm not sure, to FINALLY get that document approved, and to PR4

FINALLY be able to circulate it. And in the end, it was never really broadly circulated, it sounds like, to those you know, to P3 all levels of people involved in cancer care and screening. So it's very unfortunate. And it was, I think by now it got to the appropriate recipients and it's had its effect but it could have had even more impact if we, if a communication strategy had been ironed out.

I mean, the overwhelming one [challenge] is the inability for the health boards to provide colonoscopy. That's, that's it
really. The, the actual central laboratory runs really well, we don't have any problems with it. The, the turnover is very fast P12
and the quality control checks have all been very good. So, it's not, it's not an issue with the actual screening centre, it's
all-around colonoscopy capacity. And one of the challenges ... is the variability between the different health boards in
terms of colonoscopy waiting times. And that is something that, I suspect will be exaggerated in the coming months.

participant noted, 'always concerns about quality' but during the pandemic, 'routine quality assurance activities-visits, measuring of standards... assessment of data, the regular meeting and things was very significantly stepped back' (P18). There was tension within the 'adapting' strategy; for example, prioritising to increase colonoscopy capacity conflicted with the 'overwhelming inability for health boards to provide colonoscopy capacity' (P12). Participants also acknowledged that rationing colonoscopies might lead to missed cancers or stage shifts (P7).

Our analysis suggests some characteristics of nimbler programmes. Although some participants described their programmes and organisations as 'large', 'bureaucratic', 'clunky' and not very nimble (P19), if they managed the entire CRC screening process, they were arguably more effective than those with only partial management (invitations, kit distributions). Programmes with highly integrated communications systems (with programmes, health boards, GPs and hospitals), that had resources to do additional, ample modelling and monitoring, that were highly automated and integrated, and with smaller populations appeared to be nimbler. All programmes could easily 'turn off the tap' (P2, P3) of invite/recall letters but highly integrated programmes had more flexibility, they could more effectively manage the uneven regional effects of COVID-19 and its 'marked inequalities' (P12) because they could monitor national and local capacity, align invitations with capacity and offer patients flexibility in accessing colonoscopies based on local COVID-19 infection numbers.

\section{DISCUSSION}

Using qualitative data from a study of international CRC programme leaders and experts, we developed a conceptual framework for understanding how CRC programmes responded to the initial phase of the COVID-19 pandemic useful for management of future pandemics or other health crises. The Nimble Approach framework is defined by four concepts: Fast, Adapting, Calculating and Ethically Mindful. Although the approach includes activities that CRC programmes may have used prior to the pandemic (adapting and calculating), the rate and intensity with which these were implemented and exemplified in practice was accelerated during this time.

The findings align with published accounts of responses by individual breast, cervical, colorectal and lung cancer screening programmes. ${ }^{6} \begin{array}{llllll}17 & 19 & 20 & 22-41 & \text { The literature }\end{array}$ ranged from reports from individual screening clinics or jurisdictions, to national cancer screening approaches. For example, Acuti Martellucci et $a p^{33}$ describe their approach to quickly adapt the cervical cancer screening programme in Ancona to accommodate social distancing and avoid potential overcrowding. This included a change from non-fixed to fixed appointment time slots. ${ }^{33}$ The national breast and CRC screening programmes in the Netherlands were suspended on 16 March 2020 and invitations for screening were gradually restarted beginning in May 2020. ${ }^{64042}$ In Australia, the pandemic has not widely affected kit distribution which is mailed to participants. ${ }^{19}$ However, a lower kit return rate and challenges with colonoscopy resources have been noted during this time as staff were redeployed to help in other critical areas. ${ }^{19}$ These accounts allude to two of the main challenges that programmes across jurisdictions will likely need to address even after the pandemic, which are lower participation in CRC screening and the backlog in diagnostic follow-up that has been aggravated by this crisis. ${ }^{43}$

Our findings provide a more fulsome understanding of the many adaptive approaches taken by screening programmes during this time and illustrate some key characteristics for nimbler programmes. For example, being able to manage the entire CRC screening process, having integrated communications internally and with key external stakeholders and automated processes facilitated the nimbler response. Designing programmatic screening programmes to enable rapid adaptation can help ensure programmes are set-up and better prepared in anticipation of future waves of the COVID-19 pandemic or other crises. This is in alignment with lessons learnt from other disasters in regard to interruption of cancer screening services. ${ }^{44}$ Using the Nimble Approach is also likely to mitigate the impact of COVID-19 on incidence and mortality as modelling studies show that screening 
programmes that can minimise delays have a more modest impact on these outcomes. ${ }^{45-49}$ However, impact on other outcomes like stage of diagnosis are likely inevitable for those with delayed diagnosis.

The tensions raised by study participants in trying to be nimble included a variety of ethical dilemmas around invitations, testing and capacity management. Programmes needed to make calculated decisions about whether to invite people to (re)screen, however, they also needed to consider prioritisation of those requiring diagnostic follow-up. This dilemma was further complicated by the anxiety and stress that some patients may experience when waiting with positive results and the local effects of COVID-19 on resources and capacity. Our study suggests that while these decisions can be extremely challenging, they are important and necessary considerations to being fast, adapting, calculating and ethically mindful. A prioritisation model for CRC screening and colonoscopy follow-up was essential during this time and has also been alluded to by others. ${ }^{1835445051}$ The need for this type of prioritisation protocol is likely to extend to other crises and may also be useful in addressing the lingering backlog in screening and diagnosis resulting from the pandemic. ${ }^{43}{ }^{52}$ For example, Kadakuntla $e t a l^{55}$ suggest additional stratification risk factors than what the participants in our study mentioned, including obesity, race/ethnicity, personal medical history, lifestyle and dietary factors. Walker et $a t^{43}$ were also able to identify which groups were more likely to experience diagnostic delay in 2020 which included those in the oldest age category, those in lower-income neighbourhoods and those likely living on a First Nation reserve. Being able to quickly revise prioritisation protocols to respond to resource capacity limitations in real-time is facilitated by being fast, adapting, calculating and ethically mindful and programmes that have processes in place to swiftly pivot and revise protocols are likely to maximise their limited resources.

The utility of the Nimble Approach framework may extend beyond pandemic/crisis planning as screening programmes will also need to recover from the pandemic effectively and creatively by addressing the backlog in screening and diagnosis and ramping up screening participation. ${ }^{43} 53$ Additionally, the pandemic has also changed the landscape of primary care with the very rapid transition to virtual care/telehealth in some jurisdictions, which may require further adaptations from the programmatic screening perspective to align CRC screening delivery processes with these new processes. Moreover, this framework may be useful in responding to other unexpected issues, for example, the unexpectedly high rate of false positive results experienced in British Columbia's CRC screening programme. ${ }^{54}$ These types of adaptations to programmatic screening programmes are likely to require many innovative solutions and the Nimble Approach could be used to facilitate this process and response.

\section{Strengths and limitations}

The conceptual framework offers an understanding of how CRC programme leaders managed their programmes during the initial phase of COVID-19. The framework has relevance for other contexts, ones that are characterised by emerging and emergent health crisis, fluidity and uncertainty. It also has relevance for other screening programmes that encounter emergency situations, crises that involve complex systems and healthcare processes that entail stepwise procedures. Our study consists of data from a sample of screening programmes, with good representation across jurisdictions (North America, Europe and Australasia) and diverse roles and responsibilities across the CRC screening continuum (programme managers/leaders, experts, researchers and clinicians). While not all participants were decisionmakers, our sample included 7 distinct programmes and 19 key informants providing an in-depth understanding of the challenges programmes faced and actions taken from a variety of perspectives. The interviews were conducted during the early phases of the pandemic (March to December 2020), thus our findings and the conceptual framework are reflective of that specific point in time.

\section{CONCLUSION}

The Nimble Approach framework that was developed from our analysis of the study data offers guidance for programme leaders during the current COVID-19 pandemic about the balancing necessary to respond to a constantly evolving and uncertain situation. Acting quickly (fast), responding flexibly (adapting) and modelling and monitoring programmes (above that done as routine programmatic monitoring) to inform decisionmaking (calculating) is done while being mindful of how decisions are likely to impact the population (ethically mindful). The framework reflects the experiences of the initial phases of the pandemic but it has utility for the ongoing COVID-19 pandemic, future pandemics and other crises where challenges on healthcare resources and endoscopy capacity are likely imminent and additional capacity to continue addressing backlog in diagnostic delay is needed. Further research is needed to more fully develop and grow the utility of the framework including evaluation of the framework against screening outcomes and comparison of performance across programmes with various approaches.

\section{Author affiliations}

${ }^{1}$ The University of Melbourne School of Population and Global Health, Melbourne, Victoria, Australia

${ }^{2}$ St Michael's Hospital Li Ka Shing Knowledge Institute, Toronto, Ontario, Canada ${ }^{3}$ Graduate Department of Pharmaceutical Sciences, University of Toronto, Leslie Dan Faculty of Pharmacy, Toronto, Ontario, Canada

${ }^{4}$ University of Toronto Institute of Health Policy Management and Evaluation, Toronto, Ontario, Canada

${ }^{5}$ Department of Medicine, The Ottawa Hospital, University of Ottawa, Ottawa, Ontario, Canada 
${ }^{6}$ Cancer Care Ontario, Prevention and Cancer Control, Ontario Health, Toronto, Ontario, Canada

${ }^{7}$ Department of Medicine, University of Toronto, Toronto, Ontario, Canada ${ }^{8}$ Department of Medicine, Sunnybrook Health Sciences Centre, Toronto, Ontario, Canada

Contributors NNB contributed to the conception and design of the work, acquisition and interpretation of the data, drafting of the manuscript and revising it for important intellectual content and approval of the final version submitted. NNB also obtained funding for the work and is the guarantor of the article. MF contributed to the conception and design of the work, acquisition, analysis and interpretation of the data, drafting of the manuscript and revising it for important intellectual content and approval of the final version submitted. AR contributed to the interpretation of data, drafting of the manuscript and revising it for important intellectual content and approval of the final version submitted. NAB contributed to the analysis and interpretation of the data, revising the manuscript for important intellectual content and approval of the final version submitted. AS contributed to the acquisition of the data, revising the manuscript for important intellectual content and approval of the final version submitted. $A B$ contributed to the analysis and interpretation of data, revising the manuscript for important intellectual content and approval of the final version submitted. CD contributed to the conception and design of the work, revising of the manuscript for important intellectual content and approval of the final version submitted. LR contributed to the conception and design of the work, revising of the manuscript for important intellectual content and approval of the final version submitted. JT contributed to the conception and design of the work, interpretation of the data, revising of the manuscript for important intellectual content and approval of the final version submitted.

Funding This work was supported by Canadian Institutes of Health Research (CIHR) grant funding no. \#148470.

Disclaimer The funder had no role in the conception, data collection, interpretation, and reporting of the study.

Competing interests None declared.

Patient consent for publication Not applicable.

Ethics approval This study involves human participants and was approved by Unity Health Toronto - REB\#20-117. Participants gave informed consent to participate in the study before taking part.

Provenance and peer review Not commissioned; externally peer reviewed.

Data availability statement Data are available upon reasonable request. The data that support the findings of this study are available on request from the corresponding author, (NNB). The data are not publicly available due to them containing information that could compromise the privacy of research participants.

Supplemental material This content has been supplied by the author(s). It has not been vetted by BMJ Publishing Group Limited (BMJ) and may not have been peer-reviewed. Any opinions or recommendations discussed are solely those of the author(s) and are not endorsed by BMJ. BMJ disclaims all liability and responsibility arising from any reliance placed on the content. Where the content includes any translated material, BMJ does not warrant the accuracy and reliability of the translations (including but not limited to local regulations, clinical guidelines, terminology, drug names and drug dosages), and is not responsible for any error and/or omissions arising from translation and adaptation or otherwise.

Open access This is an open access article distributed in accordance with the Creative Commons Attribution Non Commercial (CC BY-NC 4.0) license, which permits others to distribute, remix, adapt, build upon this work non-commercially, and license their derivative works on different terms, provided the original work is properly cited, appropriate credit is given, any changes made indicated, and the use is non-commercial. See: http://creativecommons.org/licenses/by-nc/4.0/.

ORCID iD

Nancy N Baxter http://orcid.org/0000-0003-4793-4620

\section{REFERENCES}

1 Mathews KS, Seitz KP, Vranas KC, et al. Variation in initial U.S. Hospital responses to the coronavirus disease 2019 pandemic. Crit Care Med 2021;49:1038-48.

2 Indolfi G, Stivala M, Lenge M, et al. Impact of SARS-CoV-2 pandemic and strategies for resumption of activities during the second wave of the pandemic: a report from eight paediatric hospitals from the echo network. Front Public Health 2021;9:630168.

3 Gomez D, Dossa F, Sue-Chue-Lam C, et al. Impact of COVID 19 on the provision of surgical services in Ontario, Canada: populationbased analysis. Br J Surg 2021;108:e15-17.

4 COVID-19 significantly impacts health services for noncommunicable diseases, 2020. Available: https://www.who. int/news/item/01-06-2020-covid-19-significantly-impacts-healthservices-for-noncommunicable-diseases

5 Puricelli Perin DM, Elfström KM, Bulliard J-L, et al. Early assessment of the first wave of the COVID-19 pandemic on cancer screening services: the International cancer screening network COVID-19 survey. Prev Med 2021;151:106642.

6 Dinmohamed AG, Cellamare M, Visser O, et al. The impact of the temporary suspension of national cancer screening programmes due to the COVID-19 epidemic on the diagnosis of breast and colorectal cancer in the Netherlands. J Hematol Oncol 2020;13.

7 Alkatout I, Biebl M, Momenimovahed Z, et al. Has COVID-19 affected cancer screening programs? A systematic review. Front Oncol 2021;11:675038.

8 Chiu H-M, Su C-W, Hsu W-F, et al. Mitigating the impact of COVID-19 on colorectal cancer screening: organized service screening perspectives from the Asia-Pacific region. Prev Med 2021;151:106622.

9 Screening programmes: a short guide. increase effectiveness, maximize benefits and minimize harm, 2020. Available: https://apps. who.int/iris/bitstream/handle/10665/330829/9789289054782-eng. pdf

10 Miles A, Cockburn J, Smith RA, et al. A perspective from countries using organized screening programs. Cancer 2004;101:1201-13.

11 Gi endoscopy activity and COVID-19: next steps, 2020. Available: https://www.bsg.org.uk/covid-19-advice/gi-endoscopy-activity-andcovid-19-next-steps/

12 Morris EJA, Goldacre R, Spata E, et al. Impact of the COVID-19 pandemic on the detection and management of colorectal cancer in England: a population-based study. Lancet Gastroenterol Hepatol 2021;6:199-208.

13 Stevens SP. Important and urgent - next steps on NHS response to COVID-19, 2020. Available: https://www.england.nhs.uk/ coronavirus/wp-content/uploads/sites/52/2020/03/urgent-nextsteps-on-nhs-response-to-covid-19-letter-simon-stevens.pdf

14 Pandemic planning clinical guideline for patients with cancer, 2020. Available: https://www.cancercareontario.ca/en/guidelines-advice/ types-of-cancer/64736

15 Population screening programmes temporarily on hold, 2020. Available: https://www.rivm.nl/en/news/population-screeningprogrammes-temporarily-on-hold

16 You are not on this path alone: cancer care continues in the midst of COVID-19, 2020. Available: http://www.bccancer.bc.ca/about/newsstories/news/2020/you-are-not-on-this-path-alone-cancer-carecontinues-in-the-midst-of-covid-19

17 Patel S, Issaka RB, Chen E, et al. Colorectal cancer screening and COVID-19. Am J Gastroenterol 2021;116:433-4.

18 Habib Bedwani N, English W, Coda S, et al. Developing a prioritization model for endoscopy and colorectal cancer 2week wait referrals during the COVID-19 pandemic-is faeca immunochemical testing the answer? Br J Surg 2021;108:e18-19.

19 Feletto E, Grogan P, Nickson C, et al. How has COVID-19 impacted cancer screening? adaptation of services and the future outlook in Australia. Public Health Res Pract 2020;30. doi:10.17061/ phrp3042026. [Epub ahead of print: 0912 2020].

20 Del Vecchio Blanco G, Calabrese E, Biancone L, Del Vecchio G, Blanco E, et al. The impact of COVID-19 pandemic in the colorectal cancer prevention. Int J Colorectal Dis 2020;35:1951-4.

21 Turnbull C. Effect of COVID-19 on colorectal cancer care in England. Lancet Gastroenterol Hepatol 2021;6:152-4.

22 Villain P, Carvalho AL, Lucas E, et al. Cross-Sectional survey of the impact of the COVID-19 pandemic on cancer screening programs in selected low- and middle-income countries: study from the IARC COVID-19 impact Study Group. Int J Cancer 2021;149:97-107.

23 Yin RK. Case study research : design and methods. Thousand Oaks, Calif.: Sage Publications, 2009.

24 O'Brien BC, Harris IB, Beckman TJ, et al. Standards for reporting qualitative research: a synthesis of recommendations. Acad Med 2014;89:1245-51.

25 Poland BD. Transcription quality as an aspect of rigor in qualitative research. Qualitative Inquiry 1995;1:290-310.

26 Patton MQ. Qualitative evaluation and research methods. 2nd ed. Thousand Oaks, CA, US: Sage Publications, Inc, 2002. 
27 Guest B BA, Johnson L. How many interviews are enough?: an experiment with data saturation and variability. Field Methods 2006;18:59-82.

28 Kuzel AJ. Sampling in qualitative inquiry. In: Doing qualitative research. Thousand Oaks, CA, US: Sage Publications, Inc, 1999: 31-44.

29 Charmaz K. Constructing Grounded theory: a practical guide through qualitative analysis. SAGE Publications, 2006.

30 Khan Samia VR. Cultivating the Under-Mined: Cross-Case Analysis as Knowledge Mobilization. In: Forum qualitative Sozialforschung / Forum: qualitative social research. 9, 2008.

31 Ayres L, Kavanaugh K, Knafl KA. Within-case and acrosscase approaches to qualitative data analysis. Qual Health Res 2003;13:871-83.

32 Basu P, Alhomoud S, Taghavi K, et al. Cancer screening in the coronavirus pandemic era: adjusting to a new situation. JCO Glob Oncol 2021;7:416-24

33 Acuti Martellucci C, Morettini M, Flacco ME, et al. Delivering cervical cancer screening during the COVID-19 emergency. BMJ Sex Reprod Health 2021;47:296-299.

34 Milanese G, Sabia F, Sestini S, et al. Feasibility and safety of lung cancer screening and prevention program during the COVID-19 pandemic. Chest 2021;160:e5-e7.

35 Kadakuntla A, Wang T, Medgyesy K, et al. Colorectal cancer screening in the COVID-19 era. World J Gastrointest Oncol 2021;13:238-51.

36 Nyante SJ, Benefield TS, Kuzmiak CM, et al. Population-level impact of coronavirus disease 2019 on breast cancer screening and diagnostic procedures. Cancer 2021;127:2111-21.

37 As pandemic continues, screening concerns grow. Cancer Discov 2021;11:pp. 214--215.

38 Miller MJ, Xu L, Qin J, et al. Impact of COVID-19 on Cervical Cancer Screening Rates Among Women Aged 21-65 Years in a Large Integrated Health Care System - Southern California, January 1-September 30, 2019, and January 1-September 30, 2020. MMWR Morb Mortal Wkly Rep 2021;70:109-13.

39 Song H, Bergman A, Chen AT, et al. Disruptions in preventive care: mammograms during the COVID-19 pandemic. Health Serv Res 2021;56:95-101.

40 Dinmohamed AG, Visser O, Verhoeven RHA, et al. Fewer cancer diagnoses during the COVID-19 epidemic in the Netherlands. Lancet Oncol 2020;21:750-1.

41 Campbell C, Sommerfield T, Clark GRC, et al. COVID-19 and cancer screening in Scotland: a national and coordinated approach to minimising harm. Prev Med 2021;151:106606.
42 Kortlever TL, de Jonge L, Wisse PHA, et al. The National FIT-based colorectal cancer screening program in the Netherlands during the COVID-19 pandemic. Prev Med 2021;151:106643.

43 Walker MJ, Meggetto O, Gao J, et al. Measuring the impact of the COVID-19 pandemic on organized cancer screening and diagnostic follow-up care in Ontario, Canada: a provincial, population-based study. Prev Med 2021;151:106586.

44 Puricelli Perin DM, Christensen T, Burón A, et al. Interruption of cancer screening services due to COVID-19 pandemic: lessons from previous disasters. Prev Med Rep 2021;23:101399.

45 de Jonge L, Worthington J, van Wifferen F, et al. Impact of the COVID-19 pandemic on faecal immunochemical test-based colorectal cancer screening programmes in Australia, Canada, and the Netherlands: a comparative modelling study. Lancet Gastroenterol Hepatol 2021:6:304-14.

46 Kregting LM, Kaljouw S, de Jonge L, et al. Effects of cancer screening restart strategies after COVID-19 disruption. Br J Cancer 2021;124:1516-23

47 Yong JH, Mainprize JG, Yaffe MJ, et al. The impact of episodic screening interruption: COVID-19 and population-based cancer screening in Canada. J Med Screen 2021;28:100-7.

48 Breast Screening Working Group (WG2) of the Covid-19 and Cancer Global Modelling Consortium, Figueroa JD, Gray E, et al. The impact of the Covid-19 pandemic on breast cancer early detection and screening. Prev Med 2021;151:106585.

49 Jen GH-H, Yen AM-F, Hsu C-Y, et al. Modelling the impacts of COVID-19 pandemic on the quality of population-based colorectal cancer screening. Prev Med 2021:151:106597.

50 Miglioretti DL, Bissell MCS, Kerlikowske K, et al. Assessment of a Risk-Based approach for triaging mammography examinations during periods of reduced capacity. JAMA Netw Open 2021;4:e211974

51 Croswell JM, Corley DA, Lafata JE, et al. Cancer screening in the U.S. through the COVID-19 pandemic, recovery, and beyond. Prev Med 2021;151:106595

52 Marcondes FO, Cheng D, Warner ET, et al. The trajectory of racial/ ethnic disparities in the use of cancer screening before and during the COVID-19 pandemic: a large U.S. academic center analysis. Prev Med 2021;151:106640.

53 Castanon A, Rebolj M, Pesola F, et al. Recovery strategies following COVID-19 disruption to cervical cancer screening and their impact on excess diagnoses. Br J Cancer 2021;124:1361-5.

54 G. Society. BC colorectal cancer screening test suspended, 2017. Available: https://badgut.org/bc-colorectal-cancer-screening-testsuspended/ 